\title{
DE SUD A SUD: LA INFLUĖNCIA DE LA DONA AMAZIGA EN L'EDUCACIÓ INFORMAL DE LES FAMILIES, EL CAS DEL MUNICIPI DE TORTOSA (BAIX EBRE)
}

ILENE GLASSER MARTINEZ

Màster d'Antropologia Urbana, Migracions i Intervenció Social iglassermartinez@gmail.com·https://orcid.org/000o-0001-6509-339X

RESUM. Aquest article neix com a continuïtat i embranzida del treball final del Màster d'Antropologia Urbana, Migracions i Intervenció Social i té com a objectiu fer una síntesi de la feina etnogràfica feta durant els 15 mesos d'anàlisi del collectiu amazic del sud-est del Marroc present a Tortosa. Amb un enfocament clau en la tasca que desenvolupen les mares com a garants de la perpetuïtat de les tradicions en l'àmbit familiar. Des d'aquesta vessant, es fa una anàlisi teòrica en l'àmbit de l'antropologia cultural en un context migratori, amb l'anàlisi de l'etnografia realitzada tant en l'espai públic com en els espais privats. Un element essencial en aquest treball és la informació obtinguda a partir dels relats i les experiències reals de les persones entrevistades, a partir de les quals s'analitzen i es fonamenten les aportacions teòriques.

PARAUlES ClAU: educació informal; transmissió cultural; dona; amaziguitat; Tortosa. 
From South to South: the Influence of Amazigh Women on the Informal Education of Families. The Case of Tortosa (Baix Ebre, Catalonia)

ABSTRACT. This article is a continuation of a thesis written for the Master's Degree in Urban Anthropology, Migration and Social Intervention and synthesizes ethnographic work done over 15 months among the Amazigh community in Tortosa. The primary focus of the study is on the role of mothers as those who guard and ensure the perpetuation of traditions within the family. To examine this, the study undertakes a theoretical analysis of migration-related ethnography carried out in both public and private spaces in the field of cultural anthropology. An essential element of the work is the information obtained from the stories and real experiences of the interviewees, which in turn are related to the analysis of the theoretical contributions.

KEYWORDs: informal education; cultural transmission; women; Amazigh community; Tortosa. 


\section{Introducció}

Quan des del món de les ciències socials s'aborden els processos migratoris, sovint es donen per fet algunes dinàmiques, com si fossin reproduccions del que es feia en origen. Una d'aquestes és la transmissió cultural, la qual dona peu a pensar que els fills reprodueixen, més bé o més malament, la identitat que era pròpia dels seus pares. Un dels objectius d'aquest treball és posar en evidència que la transmissió no és una qüestió que es troba en disputa, que no s'aplica de manera automàtica, que es troba subjecta a condicionants diversos i que, com a conseqüència, provoca expressions identitàries que no sempre es reprodueixen en els paràmetres familiars.

Malgrat que des d'aquest àmbit és una qüestió àmpliament treballada, es continua debatent la manera d'abordar el significat de processos de transmissió i creació d'identitats, aplicant (encara) de manera extensiva -inclús entre els experts - el concepte de segones generacions, i no el de fills de pares immigrants, que, sense un origen migrant, suposadament conserven les tradicions, la llengua i (a vegades) la religiositat dels seus pares, i per la qual cosa sembla que acaben "heretant" la condició de migrant familiar.

L'estudi que emmarca aquest article pretén, a partir d'una anàlisi etnogràfica, fonamentar teòricament el procés evolutiu de la transmissió identitària i l'assumpció de rols en aquest sentit des del punt de vista matern, contextualitzat en la comunitat migrada amaziga del sud-est marroquí present al municipi de Tortosa (Baix Ebre). A partir d'una anàlisi contextual i demogràfica, es presenta l'evolució de la presència de la comunitat marroquina a Catalunya i com ha realitzat un procés clar d'assentament i deslocalització. La presència femenina en el mateix collectiu, a partir dels reagrupaments familiars als anys 2000, ha esdevingut un factor essencial en el canvi de perspectiva d'anàlisi de la representativitat de la comunitat; així, ha passat de considerar-se migració laboral masculina a comunitat migrada amb projectes familiars i d'estabilització al territori.

La qüestió identitària del collectiu passa per la seva definició, com a amazics i alhora marroquins, amb la reivindicació de diferenciar-se d'allò 
que representa l'arabització. Tot i això, la religió (l'islam) ha esdevingut un element unificador entre àrabs i amazics, els quals comparteixen creences i festivitats religioses. En aquest sentit, les famílies amazigues del sud-est marroquí, les quals han estat centre del present estudi, conformen un espai familiar reconstruït amb una connexió i un retrobament constant amb l'origen, el qual busquen perpetuar i fer romandre a partir de la transmissió religiosa i cultural dels progenitors cap als seus fills i filles. Es planteja en aquest sentit la qüestió de la transmissió d'un bagatge cultural, d'una cultura que des de la perspectiva antropològica esdevé un subjecte que cal que sigui analitzat i com un element líquid, modificable i adaptable a cada membre que en forma part, tenint en compte els estímuls aliens al grup i que cada individu absorbeix del seu context (Camilleri, 1985).

L'eix transversal que s'emmarca en l'argumentari de la transmissió de valors i la prevalença d'allò que és incorporat des del país d'origen se centra en la figura femenina de la mare, ja que s'estableix una clara diferència entre quin és el paper que assumeix l'home (pare) i quin és el que té atorgat la dona (mare). Les dones amazigues que han d'exercir el paper de mare en un context social que els és desconegut es presenten com les principals responsables de la construcció identitària dels seus fills i filles, i han de fer front als equilibris que s'han de forjar entre la cultura i tradicions de l'origen i el projecte familiar i de vida en la societat catalana. A través de l'argumentari matern es presenta quins són els neguits i les preocupacions de les dones en relació amb la interacció dels fills i filles amb el context de rebuda, així com quina és la seva capacitat per poder "estar a l'alçada" d'allò que li requereix la societat majoritària.

S'exposa en els propers apartats el detall de la metodologia, la base empírica de la investigació, així com la recerca i anàlisi etnogràfica en el context comunitari de Tortosa. 


\section{Metodologia de treball}

La recerca per a aquest article es fonamenta en un treball de camp que es troba encara obert, precedit pel treball final del màster d'Antropologia, Migracions i Intervenció Social i amb l'objectiu de ser una introducció en l'elaboració de la tesi doctoral en l'àmbit de les migracions. La feina etnogràfica realitzada fins al moment de l'elaboració d'aquest article s'ha desenvolupat partint de les premisses metodològiques (seguint les recomanacions de Taylor i Bogdan, 1984) d'una interacció no ofensiva en el camp, aprofitant la participació de la part investigadora en les classes de llengua que s'ofereixen al municipi de Tortosa; l'ús de tècniques d'investigació qualitativa, com l'entrevista en profunditat i l'observació participativa durant l'accés a espais privats i íntims de les persones entrevistades, $i$, finalment, un bon ús de les notes i registre de l'activitat observada.

Sobre la base de l'objecte principal de la investigació, es defineix el perfil de les persones que representen la part etnografiada; tenint en compte la voluntat d'analitzar la transmissió de valors culturals, morals i tradicionals de les mares migrades amazigues cap als fills i filles en un escenari descontextualitzat, s'ha seleccionat un perfil de dona adulta d'entre $35 \mathrm{i}$ 55 anys, la qual ha format part d'un procés de reagrupament familiar. La zona d'origen de les persones informants és el sud-est marroquí i formen part de l'ètnia amaziga; a més, els anys d'emigració d'aquestes persones són entre el 2004 i el 2010, és a dir, totes fa més de deu anys que viuen a Catalunya.

A continuació es presenta un quadre resum de les persones entrevistades en el marc de la recerca: 


\begin{tabular}{|c|c|c|c|c|c|}
\hline Informant & Edat & $\begin{array}{l}\text { Projecte } \\
\text { migratori }\end{array}$ & Fills i filles & Ocupació & Observacions \\
\hline Samira & 37 & $\begin{array}{l}\text { Reagrupació } \\
\text { familiar } \\
(2006)\end{array}$ & $\begin{array}{l}23 \hat{\jmath} \text { (fillas- } \\
\text { tre), } 14 \text { ㅇ, } 13 \text { 우 } \\
11 ㅇ, 8 \text {, } 3{ }^{\circ}\end{array}$ & $\begin{array}{l}\text { Cura de la llar } \\
\text { i els fills. }\end{array}$ & $\begin{array}{l}\text { En context familiar hi pre- } \\
\text { domina l'idioma amazic. } \\
\text { Parla el català, no sap ni } \\
\text { l'àrab ni el castellà de mane- } \\
\text { ra fluida però els comprèn. } \\
\text { No ha estat escolaritzada. } \\
\text { Participa en l'àmbit comu- } \\
\text { nitari i en les classes de } \\
\text { català de l'Ajuntament. El } \\
\text { marit treballa a fora, per } \\
\text { la qual cosa passa temps } \\
\text { sense l'acompanyament de } \\
\text { l'home. } \\
\text { Paper important de la reli- } \\
\text { gió en l'educació familiar. }\end{array}$ \\
\hline Salima & 43 & $\begin{array}{l}\text { Reagrupació } \\
\text { familiar } \\
(2010)\end{array}$ & $18 \widehat{\partial}, 15 \widehat{\partial}, 8$ q & $\begin{array}{l}\text { Cura de la } \\
\text { llar i els fills. } \\
\text { Treballa fent } \\
\text { tasques de } \\
\text { neteja en } \\
\text { altres llars, } \\
\text { de manera } \\
\text { irregular i } \\
\text { temporal. }\end{array}$ & $\begin{array}{l}\text { En context familiar hi } \\
\text { predomina l'idioma ama- } \\
\text { zic. Parla l'àrab i ha estat } \\
\text { escolaritzada al Marroc. El } \\
\text { català i el castellà els domi- } \\
\text { na sense fluïdesa. Participa } \\
\text { de manera activa en l'àmbit } \\
\text { comunitari i en les classes } \\
\text { de català de l'Ajuntament de } \\
\text { Tortosa. } \\
\text { Paper important de la reli- } \\
\text { gió en l'educació familiar. }\end{array}$ \\
\hline Titrit & 37 & $\begin{array}{l}\text { Reagrupació } \\
\text { familiar } \\
(2008)\end{array}$ & $70 \hat{0}, 90$ & $\begin{array}{l}\text { Cura de la llar } \\
\text { i els fills. Vol } \\
\text { treballar però } \\
\text { el seu marit } \\
\text { considera que } \\
\text { no és neces- } \\
\text { sari. }\end{array}$ & $\begin{array}{l}\text { En context familiar hi pre- } \\
\text { domina l'idioma amazic i } \\
\text { l'àrab. Parla en amazic amb } \\
\text { els fills. El castellà i el català } \\
\text { els domina sense fluïdesa. } \\
\text { Ha estat escolaritzada al } \\
\text { Marroc. Poc participativa } \\
\text { en l'àmbit comunitari, } \\
\text { actualment no acudeix a les } \\
\text { classes. } \\
\text { Presència de la religió en } \\
\text { l'educació familiar, però no } \\
\text { hi adopta un paper relle- } \\
\text { vant. }\end{array}$ \\
\hline
\end{tabular}




\begin{tabular}{|c|c|c|c|c|c|}
\hline Informant & Edat & $\begin{array}{l}\text { Projecte } \\
\text { migratori }\end{array}$ & Fills i filles & Ocupació & Observacions \\
\hline Abdel & 52 & $\begin{array}{l}\text { Motius labo- } \\
\text { rals (2004) }\end{array}$ & $\begin{array}{l}\text { Marit de Titrit. } \\
7 \hat{\delta}, 9 \hat{\delta}\end{array}$ & $\begin{array}{l}\text { Enginyer en } \\
\text { multinacional } \\
\text { tecnològica } \\
\text { marroquina, } \\
\text { represen- } \\
\text { tant d'as- } \\
\text { sociacions } \\
\text { amazigues al } \\
\text { Marroc. }\end{array}$ & $\begin{array}{l}\text { En context familiar hi pre- } \\
\text { domina l'idioma amazic i } \\
\text { l'àrab. Parla l'àrab amb els } \\
\text { seus fills, coneix el català i } \\
\text { el castellà de manera fluida. } \\
\text { Té estudis superiors i nivell } \\
\text { cultural avançat. } \\
\text { Presència gairebé escassa } \\
\text { de la religió en l'educació } \\
\text { familiar. }\end{array}$ \\
\hline Tuda & 53 & $\begin{array}{l}\text { Reagrupació } \\
\text { familiar. } \\
(2007)\end{array}$ & $\begin{array}{l}35 \text { ㅇ, } 30 \text { ㅇ, } 25 \text { ô, } \\
23 \text { ㅇ, } 18 \text { ㅇ. } \\
5 \text { nets. }\end{array}$ & $\begin{array}{l}\text { Cura de la } \\
\text { llar i els fills. } \\
\text { Puntualment } \\
\text { treballa } \\
\text { d'ajudant de } \\
\text { cuina en un } \\
\text { restaurant } \\
\text { de manera } \\
\text { irregular. }\end{array}$ & $\begin{array}{l}\text { En context familiar hi pre- } \\
\text { domina l'idioma amazic. } \\
\text { Poc domini de l'àrab, el } \\
\text { català i el castellà. La filla } \\
\text { (30) dona suport en l'en- } \\
\text { trevista i hi fa aportacions } \\
\text { importants. Poc participa- } \\
\text { tiva en l'àmbit comunitari, } \\
\text { actualment no acudeix a les } \\
\text { classes. } \\
\text { Presència dèbil de la religió } \\
\text { en l'educació familiar. }\end{array}$ \\
\hline
\end{tabular}

El primer accés al camp es realitza a partir de les visites a les classes de llengua catalana organitzades per l'Ajuntament de Tortosa, per part de personal de l'Ajuntament i voluntàries. En aquest context, dos grups de dones reben classes de català, en horari de tarda, quan els fills i filles es troben a l'escola. La totalitat de les usuàries són procedents del Marroc i gairebé totes procedeixen del sud-est marroquí i són amazigues; de la mateixa manera, les dues voluntàries que exerceixen de professores també són dones, amazigues i del sud-est marroquí. Els grups es conformen per dones de diferents franges d'edat. Un grup el configuren dones d'edat més adulta (a partir de 40), amb un nivell més baix d'idioma a causa del seu analfabetisme. Són les primeres dones que van arribar a Tortosa amb els reagrupaments familiars a l'inici dels anys 2000 , fet que les va fer trobar-se sense un sistema d'acollida establert i sense poder cobrir les necessitats que presentaven en relació amb la inclusió comunitària. L'altre grup el configuren dones més joves (entre 23 i 45), amb escolarització prèvia al Marroc, amb fills i filles d'edats més joves i que des de la seva arribada (més tardana que el primer grup) a Tortosa han tingut més opcions 
d'aprenentatge i coneixement de l'entorn que les anteriors, la qual cosa fa que els resultats d'aprenentatge de la llengua esdevinguin més prematurs i satisfactoris, lligat alhora a l'augment de la presència d'aquestes dones en activitats laborals.

La totalitat de les entrevistes en profunditat s'han realitzat en els espais familiars privats, fet que ha esdevingut una oportunitat per observar i comprendre com és d'important la reproducció dels elements propis del context d'origen. Poder accedir a les llars ha permès observar dinàmiques i maneres de fer que es repeteixen al si comunitari de les famílies migrades del sud-est marroquí. S'ha decidit fer constar com a informant un dels marits de les dones entrevistades, tot i que de manera generalitzada els marits no han estat presents en els espais de conversa; no obstant això, en aquest cas l'home (Abdel) ha aportat qualitat a l'entrevista, en tant que representant de la identitat amaziga i ampli coneixedor de la socialització d'aquest collectiu tant al Marroc com a Catalunya. La seva presència a l'entrevista ha servit a la part investigadora, alhora, per observar i contraposar punts de vista entre la figura materna i paterna, pel que fa a l'educació informal dels fills i filles.

En aquest sentit, la investigació qualitativa ha volgut copsar la veu de cinc protagonistes, de les quals s'ha fet prevaldre la qualitat en els relats, per sobre de la quantitat. Les entrevistes realitzades s'han estructurat partint d'un guió, tot i que també s'han incorporat altres qüestions sorgides durant les converses. El guió plantejat segueix una línia cronològica i d'història de vida de la informant: la seva presentació personal i genealògica, la descripció del seu poble d'origen, el procés migratori familiar i les expectatives formades encara a l'origen. Tanmateix, es plantegen qüestions sobre el procés d'arribada a Catalunya i Tortosa, el procés d'assentament i l'assoliment de les expectatives inicials. Pel que fa a l'àmbit familiar, interessa conèixer com és l'organització domèstica, en relació amb els fills i filles, la tasca productora i reproductora, i alhora es busca trobar enclavaments de l'origen en el context català. Es tracta de comprendre a partir del relat de les dones la visió i responsabilitat que assumeixen, com a garants de la transmissió dels orígens i la dicotomia d'educar els fills en un context que no es considera el tradicional. 
La intencionalitat de l'estudi ha estat obtenir les narracions fetes per les dones sobre les seves vides, la qual cosa ens permet comprendre millor la seva realitat i entendre la manera com es desenvolupen les pràctiques de transmissió cultural i religiosa.

\section{La transmissió de la cultura i l'educació informal en un context migratori}

En l'esfera familiar, la transmissió no conscient forma part de l'educació informal, pel que fa als valors, maneres de fer, tradicions i costums. Com a norma general, el traspàs d'hàbits comença a assimilar-se des de la infancia, tenint en compte que en aquest procés no és més important allò que es vol transmetre sinó el que acaba sent transmès, amb independència del valor i efecte que això pugui provocar en els receptors. Tanmateix, la transmissió inconscient es considera una eina per fer prevaldre la cultura, però aquest propòsit es veu altament distorsionat quan es produeix i fluctua en un context que no és l'original i on conflueixen sistemes culturals diversos, plens d'impactes externs que creen nous escenaris i dificulten la puresa de la prevalença d'un únic sistema cultural. En aquest sentit, podem parlar de crisi en el model de socialització tradicional, a partir d'un procés migratori (Herrera Aragón, 2006).

L'educació formal i la informal juguen un paper clau per al funcionament dels collectius, per tal que el sistema cultural es mantingui de manera generacional, malgrat l'aparició de nous contexts socials que reformulen els canals de transmissió i les formes en què aquests valors són transmesos (Spindler, 1987). En una comunitat en transformació cultural, la por de menystenir i pervertir l'essència de les tradicions religioses o morals de la comunitat fa que es creïn mecanismes de control i pressió per part dels mateixos membres, els quals, sense ser reconeguts formalment, són presents a l'àmbit familiar.

Tenint en compte el factor contextual que implica estar en la societat en condició de minoria, davant el seu collectiu i davant la societat catalana, la transmissió i el treball d'educació informal de les famílies d'origen migrant té un paper clau en la construcció identitària del nucli familiar i 
el seu posicionament davant del seu collectiu i davant la societat catalana. En assumir la tasca de transmetre uns valors heretats, a vegades (no sempre) s'és conscient del desajust que pot incloure aquesta transmissió en un escenari descontextualitzat i amb múltiples interaccions del context social on viuen. Sense deixar de mantenir inherents els valors i les tradicions basats en la cultura familiar del país d'origen, la qual està marcada i redefinida pel procés migratori i es mostra amb una clara expressió de nostàlgia, les famílies han d'assumir nous codis de conducta amb què els seus fills i filles també se senten identificats amb l'objectiu d'aconseguir un equilibri en l'educació familiar (Pàmies, 2006).

En un primer moment, el paper dels progenitors és clau en la definició identitària dels fills i filles; no obstant això, la pressió que s'exerceix des del context de la societat catalana (a través de la socialització educativa que reben), i també de la societat d'origen (que actua com a referència d'una identitat idealitzada), dificulten i determinen com s'acaben modelant les identitats pròpies dels fills i filles.

En el context de les famílies migrades tradicionals, de principal interès en aquest estudi, les dones migrades (reagrupades) que han d'exercir el seu paper de mare en un context social descontextualitzat al propi, acostumen a ser les principals responsables de l'educació informal i transmissió cultural a la família. A diferència d'altres collectius migrants, la marroquina pot definir-se com una migració generitzada (Gregorio Gil, 2013), tenint en compte que en la societat d'origen el sistema de gènere representa el màxim organitzador de molts àmbits de la vida i es reprodueix gairebé de la mateixa manera en el seu assentament a Catalunya. Generalment, les primeres dones arribades a Catalunya a partir dels reagrupaments familiars van mantindre lligams molt estrets amb els seus països d'origen, cosa que provocà l'establiment d'espais transnacionals interessants i complexos. Les dones marroquines mantenen una certa mobilitat transnacional, per tal com continuen sent les responsables de la cura dels pares al Marroc, cosa que les fa renunciar a les possibilitats laborals a les quals podrien aspirar en territori europeu, i assumeixen el paper reproductiu i de cura que ja predominava a l'origen (Montoro-Gurich, 2017). A través del treball de camp realitzat i de les anàlisis 
de diferents autores (Lamrabet et alii, 2020), podem explicar que aquest fenomen no es detecta de la mateixa manera amb les mares més joves, les quals han realitzat el procés migratori en una època més tardana i en un context social molt més global. Les mares més joves tenen present la perpetuïtat i importància de les tradicions, però alhora cerquen espais de reivindicació femenina en àmbits com el laboral o l'acadèmic.

En clau d'educació informal intrafamiliar i de la perpetuïtat dels trets culturals d'origen, les famílies amazigues, en aquest context familiar transnacional, han de combatre, a més, amb l'homogeneïtzació del collectiu, ja que tots els marroquins són considerats àrabs i l'amaziguitat queda relegada a un tret cultural secundari. Per aquest motiu, l'ús vehicular de la llengua amaziga a la família, la festivitat de les dates i esdeveniments propis i la reivindicació identitària formen part de la tasca transmissora principalment en mans de les mares, les quals es diferencien clarament de les dones àrabs. La dona amaziga reprodueix el rol de tamghart ('cap de família' en amazic), que és present a l'origen i es mostra principalment a l'esfera privada i en el context comunitari; en aquest sentit, l'anàlisi del paper de les dones migrades amazigues no s'entén sense tenir en compte la seva ruralitat i percepció de la vida tradicional. Les representacions i la simbologia formen part de la cultura, sobretot la significació que adopten en un context concret, tenint en compte que volen transmetre valors collectius que són compartits i a partir dels quals es crearà una imatge i definició d'un grup. Per aquest motiu, davant d'estratègies discursives i pràctiques socials que volen anullar la capacitat de garants de la tradició de les dones, creen representacions culturals subversives, com a instruments de resistència contra la subalternitat i el reconeixement identitari (Nash, 2006).

\section{Evolució de la comunitat marroquina a Catalunya}

Els primers migrants d'origen marroquí arribaren a Catalunya als anys setanta, en un context polític encara marcat i condicionat pels últims anys del franquisme. Catalunya era considerada territori de trànsit migratori cap a altres països europeus com França, tot i que, a causa del tancament de fronteres com a conseqüència de la crisi econòmica del principi de la dècada dels setanta, Barcelona es va convertir en lloc d'arribada 
i assentament de milers de marroquins que més tard van traslladar-se a municipis de la periferia com Santa Coloma de Gramenet i l'Hospitalet de Llobregat, on es trobaven les principals indústries i oportunitats laborals. A partir dels anys noranta, les persones nouvingudes ja no es dirigien a Barcelona, sinó a altres destinacions del territori català.

Els marroquins han estat i són el collectiu d'estrangers més àmpliament representat en la societat catalana des dels anys vuitanta-noranta i fins avui. L'any 2020 consta un total de 238.003 persones amb nacionalitat marroquina residint a Catalunya (INE, 2021). ${ }^{1}$ La feminització del collectiu es produeix a partir de l'any $2004 \mathrm{amb}$ un increment exponencial de la presència de les dones en les xifres estadístiques, a causa del retrobament de les famílies que s'havien separat amb el viatge incipient de l'home sol, així com dels nous matrimonis que van esdevenir en context migratori.

De la mateixa manera, ja des dels anys setanta es té constància d'un nombre important d'amazics a Catalunya, els quals provenien de la zona nord del Marroc, el Rif i de la zona del sud-est, a les muntanyes de l'Atles, sobretot de la regió del Drâa-Tafilalet. Els amazics del nord es van desplaçar majoritàriament a municipis de les comarques de l'Empordà, Osona i el Maresme, mentre que els del sud-est van assentar-se a municipis del Baix Llobregat, com Santa Coloma de Gramenet o Cornellà, i a la comarca del Baix Ebre, amb Tortosa com a principal destinació (Aixelà, 2013).

Continuant l'anàlisi del collectiu i focalitzant-lo a la comarca del Baix Ebre, ens trobem amb la capital, Tortosa, considerada el principal eix social de l'extrem sud de Catalunya. La població de Tortosa entre els anys 2000 i 2009 va experimentar un increment del $22 \%$, relacionat directament per la contribució de la població estrangera (Eixarch, 2013). L'any 2020 es troben censats a Tortosa 2.163 marroquins, d'un total de 33.439 persones (IDESCAT, 2021). ${ }^{2}$ La presència de persones d'origen marroquí va fer canviar el paisatge demogràfic del municipi, sobretot quan es conformaren les primeres famílies i per part del collectiu van reivindicar-se espais propis de representació, com els espais de culte.

1 INE. Estadística del Padrón Continuo. URL: <https://www.ine.es/jaxi/Datos.htm?path=/t20/e245/ po8/lo/\&file=03005.px\#!tabs-tabla $>$ (consulta: 2 de març de 2021).

2 IDESCAT. Població estrangera, per municipis, 2020. URL: <https://www.idescat.cat/poblacioestrangera/?b=7\&geo=prov:43\&nac $=\mathrm{d} 228>($ consulta: març de 2021$)$. 


\subsection{Representativitat i socialització en l'àmbit comunitari}

Es considera que l'espai social que ocupen les persones migrades en la societat de rebuda representa l'estat i evolució que els collectius han adaptat en relació amb el seu assentament al lloc de destinació. El paper de comunitat sorgeix a partir de l'exclusió entre collectius, producte de la desigualtat que es crea pels diferents actors del conjunt de la ciutadania; arran d'aquestes desigualtats naixen estratègies de superació i, en conseqüència, la necessitat de comunitat. Aquests elements beneficien i fomenten el consolidament $i$ assentament de comunitats que representen una minoria. Tanmateix, una forma de valor social que representen majoritàriament les comunitats de persones migrades és la religiositat com a instrument d'inserció i com a conseqüència de l'experiència d'exclusió, a partir de la qual es construiran espais on s'identifiqui la seva identitat moral o religiosa d'origen.

Jordi Moreras (2009b) fa una anàlisi sobre l'associacionisme i la representació del collectiu marroquí, que es presenta des de tres dimensions diferenciades: en relació amb la societat catalana, en relació amb el collectiu de referència i també des de la societat d'origen. El fet que els collectius de migrants presentin estructures organitzades visibles permet a la societat de rebuda considerar-los com a tals i capacitats per cobrir les seves necessitats individuals i collectives.

L’associacionisme magrebí a Catalunya s'ha relacionat partint de la transmissió de la religió, la cultura i la tradició, motius pels quals ha estat criticada i comparada amb altres collectius migrants, que tenien com a aspiracions associatives ser representants de participació política o institucional (Moreras, 2009b). Els marroquins a Catalunya es veuen representats per una llengua, tradicions i religió allunyades de la societat occidental, la qual els desconeix i els identifica a partir de judicis de valor i coneixements superficials.

Els actors i les representacions de la comunitat marroquina a Catalunya han evolucionat de la mà de les noves generacions; en l'actualitat s'ha adoptat una forma de representació que té a veure amb la seva expansió territorial i assentament definitiu, de la mateixa manera que s'hi ha multiplicat les temàtiques en les bases d'aquestes entitats, amb la creació 
de les primeres associacions de dones marroquines o sobre la base de la reivindicació de la identitat amaziga. No obstant això, un tret que continua caracteritzant l'associacionisme marroquí és la perpetuïtat del factor religiós com a eix temàtic i vehicular del collectiu, i pren la mesquita i l'oratori com a principal instrument de representació.

A Tortosa, la representació del collectiu va construir-se en un primer moment al voltant de l'oratori, on la majoria d'homes s'hi trobava i on es realitzava també l'acompanyament en tràmits burocràtics i documentals, per la qual cosa n’assumia la funció de punt de trobada religiós-comunitari.

\subsection{Els amazics del sud-est marroquí. Presència al municipi de Tortosa}

La comunitat originària del Marroc i les famílies que s'han creat en aquesta esfera comunitària a Catalunya són un exemple de context migrant permanent en el temps, que, tot i haver fet un procés clar d'assentament, continua traspassant en herència la condició de marroquí o migrant als fills i filles que han nascut o crescut fora del Marroc. A més, són també un exemple de collectiu nacional amb una heterogeneïtat ètnica interna, amb una (àmplia) minoria de persones amazigues que es diferencien de la majoria àrab.

Quan parlem de marroquins no acostumem a especificar si són amazics o són àrabs, tot i que entre ells hi ha diferències tan transcendents com la llengua: els uns parlen l'amazic i els altres parlen el darija (la variant dialectal marroquí de l'àrab). És summament descriptiu aquest detall lingüístic, ja que hi ha persones que viuen a Catalunya o hi han nascut $\mathrm{i}$ que se'ls classifica com a àrabs-marroquins, els quals no comprenen la llengua àrab, ni s'hi identifiquen. Els amazics, tot i ser un collectiu àmpliament extens al territori català, representen la minoria d'una minoria, de la mateixa manera que ho fan al país d'origen.

La Tamazgha dona nom a la terra poblada per persones amazigues al nord de l'Àfrica, que comprèn des de les illes Canàries fins a l'oasi de Siwa, a Egipte, i des del Mediterrani fins al Sahel i passa per països com Marroc, Algèria, Líbia, Egipte i Mali. La història amaziga es remet a l'antiguitat més profunda, la qual se la pot considerar autòctona del nord d’Àfrica, ja que es tenen registres de pobles amb un substrat cultural comú sobre- 
tot des del punt de vista lingüístic. Al llarg de la història han patit la invisibilització i la reivindicació d'espais propis i es fa referència a l'època postcolonial com al renaixement de la cultura amaziga a països com el Marroc i Algèria. Als anys vuitanta es van produir manifestacions amb més força en contra de la repressió a la llengua i cultura amazigues, ja que la descolonització no va ser motiu perquè els amazics continuessin estant sotmesos a l'arabització i la islamització (Castellanos i Akioud, 2007), si bé no és fins l'any 2012 quan el Marroc ha reconegut la oficialitat de la llengua amaziga al país.

Les persones amazigues han representat a Catalunya una àmplia proporció del total de marroquins al territori. No existeixen dades estadístiques del nombre d'amazics a Catalunya; no obstant això, a partir de l'anàlisi de les zones de procedència dels migrants marroquins a Catalunya, es considera que entre un $50 \%$ i un $80 \%$ són provinents de les zones amazigòfones. D'aquesta manera, diversos autors i acadèmics han considerat que la llengua amaziga podria ser la tercera més parlada a Catalunya, després del català i el castellà (Barrieras, 2013; Castellanos i Akioud, 2013).

Existeixen entitats reconegudes en l'àmbit autonòmic com la Casa Amaziga de Catalunya que han impulsat múltiples projectes pel reconeixement i l'ensenyament de l'amazic, com per exemple espais d'aprenentatge, celebracions de festivitats pròpies i l'emissió d'informatius a Barcelona TV en llengua amaziga, entre els anys 2002 i $2012 .^{3}$

Tot i no disposar de dades estadístiques concretes, els marroquins de Tortosa provenen majoritàriament de la regió Drâa-Tafilalet, amb Tinghir com a principal província de sortida i la resta de províncies de la regió: Errachidia, Zagora o Ouarzazate (López Garcia i Berriane, 2004). Es tracta d'una zona principalment rural, situada al sud-est marroquí, on gairebé la totalitat dels habitants són amazics i no àrabs, amb tradicions i llengua pròpies. La regió, segons les últimes dades, representava l'índex de pobresa més alt del país i centrava l'activitat econòmica en l'agricultura i el turisme. La taxa de continuïtat en els estudis continua sent baixa (ha millorat els últims anys), sobretot en les dones, on la necessitat de

3 Enllaç als continguts: <https://beteve.cat/general/info-amazic-taixelhit-64/> (consulta: març de 2021). 
seguir les dinàmiques establertes per la comunitat basades en l'educació informal i les tradicions tribals continua tenint un pes molt important. ${ }^{4}$

Les ciutats del sud-est marroquí van representar llocs de trobada de diferents comunitats ètniques, i per això s'hi troben encreuaments ètnics i lingüístics molt característics. La població està representada per nombrosos grups tribals, majoritàriament amazics, que alhora es deriven en diverses subtribus disperses per tot el territori. Encara avui hi trobem trets característics que identifiquen les diferents comunitats tribals, com el nomadisme d'algunes, la prevalença del dret consuetudinari en l'organització comunitària o la vestimenta i forma d'expressió de les dones (Delon, 2018).

A Tortosa la comunitat estrangera la conformava des dels anys noranta una majoria marroquina, principalment homes, i l'any 2001 es va crear el primer oratori de la ciutat, ubicat al nucli històric. Es tractava d'un local de petites dimensions que dificultava la pràctica religiosa per a tots els fidels i que els obligava en dies de gran afluència a realitzar les pregàries al carrer, i això va provocar confrontacions entre els veïns i restauradors de la zona. Després de llargues disputes i negociacions, l'any 2014 s'inaugurà la nova mesquita dirigida i gestionada per l'Associació Al Fath, conformada per persones amazigues, la qual va resultar el principal centre de culte del Baix Ebre.

A Tortosa, en l'àmbit associatiu, s'hi van crear nombroses entitats i agrupacions relacionades amb la cultura marroquina i el collectiu amazic, algunes directament relacionades amb l'ens religiós i d'altres com el Grup de Joves Amazics i Amazigues de Tortosa o entitats esportives de joves amazics, com l'Athletic Club Atlas Tortosa.

Malgrat tot aquest històric de representativitat, la realitat actual fa visible el collectiu principalment a través dels comerços i la seva presència a l'espai públic. Trobem establiments com carnisseries, cafeteries, perruqueries i tallers mecànics que són regentats per persones amazigues. Al municipi hi ha zones específiques on es troben els homes, com són els bancs i places propers a aquests comerços; alhora hi ha espais on podem trobar les dones, com parcs infantils o vies de passeig. No obstant això, l'espai de trobada feminitzat continua sent l'espai privat a les llars.

4 Dades de la Initiative Nationale de Développement Humain (INDH), del govern marroquí.. URL: $<$ http://www.indh.ma/> (consulta: març de 2021). 


\section{Les dones amazigues, paper i representació dins i fora de la llar}

Es considera la figura materna com la principal i més important pel que fa a la transmissió dels valors culturals, en les comunitats rurals, com les del sud-est marroquí; comunament al llarg de la història la dona ha d'adoptar el rol de cap de la família, tal com s'ha mencionat anteriorment, tenint en compte que els homes abandonaven la llar per motius laborals i econòmics, i es traslladaven primer a les zones urbanes del país i posteriorment viatjaven cap a Europa (López Garcia-Berriane, 2004). La dona, per tant, fou l'encarregada de tota la gestió de l'àmbit privat de la família: l'economia familiar, l'organització domèstica i d'autoabastiment, l'educació dels fills i filles i, a més, la transmissió de tots els valors morals-religiosos propis de la comunitat i de la família.

En el context d'origen, la tasca de la transmissió podia considerar-se en bona part garantida i refermada, ja que existeix un clar acompanyament comunitari. A més, l'educació formal (l'escola basada en un ensenyament tradicional) es fonamenta en els mateixos trets culturals i religiosos, així com reprodueixen i ensenyen les maneres de fer de la comunitat. Aquests fets provoquen que el conjunt dels diferents escenaris comunitaris vagin en sintonia pel que fa a la conformació identitària de les persones i al sentiment de pertinença. Malgrat el paper que adopten les dones com a cap de les famílies, la seva presència es veu reduïda de manera generalitzada a l'àmbit privat. En un context migratori, la dona (que ha realitzat un procés de reagrupació) havia d'adoptar la representació de l'imaginari d'origen respecte a les societats occidentals, i havia d'assumir la tasca matrilineal de la transmissió cultural en forma de valors, com a responsable i garant de la perpetuïtat cultural.

La qualitat de la transmissió dels valors morals, religiosos i culturals es veurà compromesa i haurà de lidiar amb interferències i situacions descontextualitzades, marcades principalment per la societat d'acollida. Les dones veuen en el procés migratori un projecte familiar obert, el qual acabaria amb el retorn als orígens, tot i que en la majoria dels casos no s'expressi la voluntat de retorn. La divisió sexual del treball es veu clarament redefinida en les famílies migrades d'origen marroquí, on l'home 
assumeix la part productora de la feina i la dona la part considerada reproductora, amb la principal tasca d'educar i fer créixer els fills, tot i que d'una manera clara contribueixen a les necessitats de la família d'una manera similar a les que són executades pels homes (Ramírez Fernández, 1998).

Tanmateix, en el nostre context d'anàlisi és determinant l'etnicitat de les famílies, com a dones amazigues amb un coneixement (generalment) bàsic o pràcticament nul de la llengua àrab, ja que l'amazic la llengua vehicular en l'educació i la vida familiar. Això fa que es trobin triplement minoritzades, pel fet de ser dones, migrades i amazigues.

Les dones amazigues que es presenten en aquest estudi es configuren com a mares de família, ja que van realitzar un projecte migratori familiar clarament definit pel viatge de l'home primer i l'assentament posterior, i el retrobament amb la dona i un o algun dels fills (si n'era el cas) al cap de pocs anys. La descripció de les primeres dones migrades és la d'una dona confiada i responsable del projecte familiar, que assumeix el paper de garant de la tradició i trasllada, de forma metaforica, en el viatge migratori tot allò que representa la identitat pròpia. La presència femenina comença a ser visible en l'entorn comunitari dels municipis en el moment que els fills assoleixen l'edat escolar, situació que els fa adoptar mecanismes per tal de comprendre nous espais de convivència que interferiran en la seva tasca educativa informal a les llars. En aquest sentit, un dels objectius més remarcables d'aquest estudi ha estat conèixer i saber de primera mà quins han estat aquests mecanismes apresos per les mateixes dones, com a garants de la transmissió, i quins neguits han anat lligats a mantindre la qualitat i eficàcia del seu paper.

L'etnografia realitzada a través de les entrevistes ha servit per conèixer $i$ aprofundir en els aspectes teòrics remarcats fins ara. La totalitat de les trobades s'han realitzat en l'espai privat familiar, fet que ha permès observar i poder desxifrar amb més cura els trets identitaris que es mantenen de l'origen. Les llars disposen com a mínim de quatre cambres; les cuines es troben separades de les sales d'estar i a totes hi ha un lloc reservat per al forn tradicional, portat des del poble i en el qual es forneja cada dia el pa. Totes disposen de tajines (recipient de fang per a cuinar) per a l'elaboració dels menjars i de cuscusera (per a l'elaboració del cus-cus). 
A la sala d'estar, els sofas són alhora cadires i una taula rodona baixa és la taula principal, que es troba rodejada pel sofa (en forma de $U$ ) i on es realitzen la totalitat dels àpats. Els sofas segueixen l'estil marroquí, majoritàriament exportats, tot i que actualment ja es poden comprar a Catalunya. A la sala d'estar s'hi accedeix sense sabates, ja que estan entapissats amb catifes, importades. Com a ornamentació hi trobem quadres i pintures de paisatges del Marroc, així com quadres religiosos amb hadits (dites del profeta Mahoma) i fragments de l'Alcorà. De manera generalitzada no acostuma a haver-hi fotografies familiars exposades.

La representació de la musulmanitat en l'entorn familiar és un dels temes analitzats a partir de les converses amb les dones entrevistades. Parlem d'un islam heretat culturalment, el qual s'allunya de grans i profundes reflexions eticomorals i que centra el discurs en un valor social, usat com a instrument d'inserció (Lacomba, 2001). Les informants expliquen que han viscut la religiositat en forma de tradicions i costums, com la celebració de les festes del sacrifici o les cerimònies, però reconeixen (sobretot les d'edat més avançada) que anys enrere seguien costums considerades tribals i que ara havien deixat de practicar per considerar-se fora dels cànons religiosos, com per exemple els tatuatges que lluïen les dones amazigues de manera habitual i que la religió no els permet.

Les dones amazigues tenien tatuatges abans. Per què l'has tret?

No vull... diuen que és haram [pecat].

I l'has tret...

Sí, a Tortosa, encara es veu una mica. Això abans no passava res i ara... Abans és obligatori, la xiqueta 8 o 9 anys ho han de ficar, diuen que si no ho fiques tindràs la cara de home... la barba... tonteries. Tenia 9 anys, li van dir que si no la volia... perquè fa mal. Se fa amb la cendra del foc... después te piquen... amb una agulla... Después agafen una herba verda, la piquen i después... per agafar el color verd. (Entrevista a Tuda i la seva filla, 2020.)

De la mateixa manera, alguns dels fills i filles de les entrevistades van o han anat a la mesquita a rebre lliçons religioses, pel fet de considerar-se una pràctica que forma part del compromís amb la comunitat. Les dones, en aquest sentit, reconeixen tenir un coneixement bàsic de la lectura 
religiosa, ja que la majoria no domina l'àrab (parlen l'amazic) i, per tant, només realitzen una pràctica i transmissió oral de la religió.

Parles àrab?

Una mica, sí... sé àrab, quan parlen l'entenc... com català. [Riu.] (Entrevista a Tuda i la seva filla, 2020.)

La manera com es transmet la importància de la pràctica religiosa ens porta a pensar en la qüestió de la tradicionalitat i herència d'aquesta pràctica; per exemple, l'ús del mocador (hijab), com a element de discussió dintre i fora de la comunitat musulmana, representa un element no tan rellevant dintre de l'entorn familiar, qüestió que ens és desconeguda:

La germana ho porta?

La menuda? No... [Riu.] No ho pensa portar mai. Jo també a vegades no el porto.

No és una qüestió que preocupi, oi?

No, jo sempre el porto, si fa calor dins de casa. És una costum... no passa res, si no hi ha homes no passa res.

Què penses que la menuda no s'ho vulgui ficar?

No passa res... [Riu.] Què canvia si portes el mocador o no? No canvia res, per a mi no... Si ella està tranquilla, no passa res. (Entrevista a Tuda la seva filla, 2020.)

La idea de socialització dels fills i filles amb l'entorn no comunitari es conforma sobre la base del desconeixement, per la qual cosa acostuma a generar-se un rebuig i omissió cap a les relacions personals d'aquests amb persones de fora de la comunitat. L'educació reglada, en aquest sentit, suposa una gran oportunitat per a ells; no obstant això, resulta també un factor desequilibrant en l'educació informal de la família, les quals hauran de coexistir en espais de socialització molt diferents. La crítica exogàmica suposa per a les mares un qüestionament continuat de la seva posició en la societat d'acollida, la qual cosa provoca distanciament i retrocés en la voluntat de voler incloure-s'hi. 
Hi ha metges que s'enfaden quan vas amb el marit també?

Sí... diuen "per què no vens sola?". [Riu avergonyida.] S'enfaden. [...] ¡Muchos son así, pero a mí no me importa! [Riu.] Alguns pregunten per què vas així, per què tens tants fills... però a mi no m’importa, si jo no faig alguna cosa mala... pues no m’importa. (Entrevista a Samira, 2020.)

En el moment de l'adolescència i la joventut és quan aquests dos espais de convivència poden arribar a confrontar $i$, per tant, és quan la mare ha d'assumir la responsabilitat de fer prevaldre els valors tradicionals i originals de la família, sense deixar que el seu fill o filla formi part del context social on viu. El fet que esdevinguin relacions afectives o sentimentals home-dona fora de la comunitat és una qüestió que les amoïna, sempre allegant la desconfiança i el neguit d'allunyar-se del que és tradicional i alhora es relaciona amb l'avergonyiment i els judicis de valor que es realitzen en l'entorn de la comunitat.

Per què creus que és difícil quan és adolescent?

Ell vol sortir per la nit... però nosaltres tenim por de quan surten per la nit, perquè és difícil, però així estava alguns anyets i ja està! Ja està passat. (Entrevista a Samira, 2020.)

Per què penses que passa? L'educació aquí és diferent?

Sí, ella fa lo que veu a fora... les amigues... només té amigues espanyoles. No està malament, malament... però... (Entrevista a Tuda i la seva filla, 2020.)

Existeix en aquest sentit una idea de protecció cap als fills i filles i simultàniament cap a les tradicions originals. Les dones entrevistades expliquen la relació i connexió que tenen amb els familiars als pobles d'origen, de manera que es desprèn quina és la presència de l'origen en les famílies emigrades, que alhora exerceixen una certa pressió en la qüestió educativa.

Des d'allà et diuen de la religió $i$ això, no?

Sí... La meva mare m’ha dit si els meus fills van a la mesquita a resar... jo li dic que sí, que van a la mesquita... (Entrevista a Salima, 2020.)

Es una manera de controlar a la gente, ¿no? 
Sí, exactamente. Y ¿qué pasa? Todos venimos, toda esta carga... venimos con toda esta carga aquí y seguro la vamos a transmitir a los hijos. ¿Qué pasa aquí? Va a haber dos fuerzas... la de la escuela, del entorno y la de dentro de la familia y depende de las personas... si están dispuestas a asumir el cambio o a... a subir en este tren o no. (Entrevista a Abdel i Titrit, intervenció de Titrit, 2020.)

Al llarg de la investigació realitzada ha esdevingut transcendental el sentit que la dona pren en la seva pròpia vida, en quina posició es colloca per si mateixa i com vol veure's projectada. Des del moment en què es pren la decisió d'emigrar fins a la qüestió d'on passar els últims anys de vida, les dones són supeditades a aquells pels quals han forjat el seu projecte de vida: la família. Les expectatives prèvies al viatge i la realitat posterior són un element remarcable en els relats de les dones.

Com pensaves que seria Espanya abans de venir?

Bonica, més que allà... [Riu.]

Pensaves que seria com és, o més facil?

Pensava més que això, pensava França, França... i mira. Però ara està bé. (Entrevista a Tuda i la seva filla, 2020.)

La incertesa del viatge hi és present sobretot pel que fa al lloc de destinació, existia el neguit i la desconfiança de poder viure com ho havien fet fins ara, en les maneres de fer pròpies als seus pobles d'origen. Segons els relats de les dones, comprovem el xoc cultural que va suposar el canvi de context i l'arribada a Tortosa.

I aleshores tu quan vas arribar aquí no coneixies ningú?

Uy! És molt difícil... quan vaig arribar plorava al meu marit: "No vull aquí!!!, vull tornar al meu país, no vull aquí..."

Sí? Ploraves? Estaves trista?

Sí... molt, molt, molt, molt... he intentat aguantar, t'estàs acostumant... poquet a poquet... he trobat algunes dones marroquines d'aquí, que els seus fills estudien on estudia el meu xiquet. Vam trobar al carrer... saludant, alguns dies venien per la tarda a la meua casa... i que difícil, molt, molt molt... quan estic embarassada d'una xiqueta... (Entrevista a Samira, 2020.) 
¿Cómo han sido los primeros días en Tortosa?

[Riu.] Molt dolent... plorant... la família... jo no puc, m’agrada la família molt. Estava plorant, dos anys no m'agrada Espanya. Jo l'he dit al meu marit, jo vull tornar al Marroc. Quan m'he quedat embarassada aquí, plorava... vaig al CAP, no sé parlar, no sé... Em fa plorar. Ha estat difícil. (Entrevista a Salima, 2020.)

Una de les maneres de mantenir les relacions amb l'origen són els viatges anuals al Marroc que totes les famílies entrevistades realitzen, els quals només s'han deixat de realitzar en algunes ocasions per qüestions econòmiques o aquests dos anys la pandèmia de la Covid-19. La "tornada a casa" suposa el retrobament, gairebé sempre, per a la celebració de la Festa del Sacrifici després del mes de Ramadà.

El perfil de les dones marroquines que es presenten és el d'una persona en trànsit entre dos mons: el de la tradicionalitat i el de la modernitat. Tots dos mons impregnats de factors que les empenyen o estiren i que les fan conscients en tot moment de les limitacions a les quals han de fer front. Assumeixen amb naturalitat la necessitat de viure i fer créixer la família lluny dels seus orígens i, pel que fa a les expectatives que tenen sobre els seus descendents, valoren i contemplen d'una manera molt realista la possibilitat que tot l'esforç realitzat perdi pes en un futur, perquè no segueixin les tradicions que els han estat forjant i inculcant des de la infantesa.

El fet que es contempli la no-culminació del projecte familiar les fa estar molt més a prop de totes les influències i inputs dels processos vitals dels seus fills i filles.

¿A ti te da miedo que un día tus hijos, cuando estés mayor y tu marido también, que no quieran ir a Marroc, se olviden un poco...? ¿Me entiendes?

Ara a mi no magrada, Imuhim, jo alsamthu lislam [els he ensenyat l'islam], quan siguin grans el que han fet, fet. Lislam diu 3lamu alauladukum [ensenyeu els vostres fills] a resar, la shahada [professió de fe]... todo. Quan siguin grans... que facin el que vulguin. (Entrevista a Salima, 2020.) 


\section{Conclusions de l'estudi}

A l'inici de l'article es fa referència a tres eixos d'anàlisi que actuen com a fil conductor en el procés de desenvolupament d'una identitat collectiva entre la comunitat amaziga de Tortosa, des del punt de vista de les mares de família.

En primer lloc, l'assentament del collectiu marroquí a Catalunya ha provocat que el mateix collectiu hagués de redefinir-se. En el context migratori, la mesquita hi té un pes important, ja que assumeix en moltes ocasions la tasca de la transmissió religiosa i moral pròpia del país d'origen, la qual no té a veure amb la transmissió dels valors culturals tradicionals. Aquests valors, segons es desprèn a les entrevistes, són transferits dintre de la família a través de l'educació informal, tasca que assumeixen les mares i que comença per la llengua materna i continua per les tradicions i els costums propis de la cultura d'origen (marroquina, musulmana i amaziga).

El segon eix conductor és la transmissió de la cultura, a partir de l'argumentari matern; es demostra una clara intenció de transmissió i d'enculturació de mare a fills, que diferencia els rols que assumeix la figura paterna i materna quant a l'educació moral. Parlem de qualitat de la transmissió de la cultura quan les dones garants de les tradicions aconsegueixen que els seus descendents assumeixin i comprenguin la seva construcció i evolució identitàries, les quals es troben en constant canvi i plenes d'influències externes, $i$, de la mateixa manera, aquells valors que han rebut en l'entorn comunitari els permetin determinar i interioritzar el sentit de les accions i la seva posició en el context on es trobin. La manera com la societat majoritària accepti i permeti l'existència d'un nou context divers serà determinant perquè l'educació cultural dintre de les famílies d'origen marroquí (i amazic) pugui tenir-hi cabuda de forma qualitativa i no pejorativa.

El tercer i últim eix transversal presenta la dona com a responsable de la transmissió; a partir de les experiències vitals de les protagonistes de l'estudi, s'ha pogut aprofundir i crear narrativa en el marc de la definició de la dona amaziga i la representativitat en l'espai privat. Des de generacions anteriors, les dones del sud-est marroquí van haver d'assu- 
mir la càrrega de dones de la llar, i això s'ha heretat a les dones migrades a Catalunya, tot i que han sabut redefinir-se i comptabilitzar la seva tasca amb la socialització i l'educació dels seus fills i filles amb entorns culturalment diversos. En aquest sentit, es pot afirmar que, sense deixar de banda la preocupació materna per educar en la tradició i la mirada posada en l'origen, sustentat en una nostàlgia heretada i un retorn imaginari, les mares comprenen i assumeixen el context en què els seus fills estan definint identitats i sentiments de pertinença basats en el context actual. Tanmateix, aquests elements tradicionals es reconfiguren en les generacions de dones més joves, que guanyen presència en l'espai públic, l'associacionisme i el mercat laboral. 


\section{Bibliografia}

Aixelà, Y. (2013) «Els amazics del Marroc», Periferia: Revista de Recerca i Formació en Antropologia, 18 (2): 81-90. Universitat Autònoma de Barcelona.

Akioud, H. i Castellanos, E. (2007) Els amazics. Una història silenciada, una llengua viva. Valls: Cossetània.

Akioud, H. i Castellanos, E. (2013) «Amazics. Identitat i llengua a l'Àfrica del nord», Diversia UPF, 3.

Barrieras, M. (2013) «La cruïlla del multilingüisme: les llengües dels catalans al segle xxI», Diversia UPF, 3 .

CAMILleRi, C. (1985) Antropología cultural y educación. Suïssa: UNESCO.

Delon, E. (2018) Carnet de recherche: Tinghir, des Berbères du Maroc. París: L'Harmattan.

Direction Générale des Collectivités Locales (2015) La Région de Drâa-Tafilalet. Monographie Generale. Ministère de l'Intérieur. Rouyaume du Maroc.

Eixarch, A. (eds.), Pallisé, A.; Ait Abou, M.; Miró, N.; Bermúdez, K. (2013) Monografia comunitària de Tortosa. "Per la millora de la convivència i la cohesió social". Tortosa: ACISI / Ajuntament de Tortosa / Xarxa per la Convivència / Obra Social "la Caixa".

GREGorio GiL, C. (1997) «El estudio de las migraciones desde una perspectiva de género» Migraciones, 1: 145-175.

Herrera Aragón, D. (2006) Experiències de socialització de fills i filles de famílies marroquines de Catalunya. Barcelona: Fundació Jaume Bofill.

ItZigSOHN, J.; GioRgULI-SAUCEDO, S. (2005) «Incorporation, transnationalism and gender: Immigrant incorporation and transnational participation as gendered processes» International Migration Review, 39 (4): 895-920.

LacombA, J. (2001) El islam inmigrado. Transformaciones y adaptaciones de las prácticas culturales y religiosas. Madrid: Secretaría General Técnica. Subdirección General de Información y Publicaciones.

LAmrabet, A. et alii. (2020) Feminismos islámicos. Bellaterra Edicions.

López Garcia, B. y Berriane, M. (dirs.) (2004) Atlas de la inmigración marroquí en España. Madrid: Observatorio Permanente de las Migraciones. Ministerio de Trabajo y Asuntos Sociales. 
Montoro-Gurich, C. (2017) «Marroquíes en España: un análisis por género de los determinantes en las migraciones familiares» Estudios Geográficos, vol. LXXVIII, 283: 445-464.

Moreras, J. (2009a) Garantes de la tradición. Viejos y nuevos roles en el ejercicio de la autoridad religiosa islámica en el contexto migratorio. El caso de Cataluña. Tesi doctoral. Tarragona: Universitat Rovira i Virgili.

Moreras, J. (2009b) Actors i representacions. L'associacionisme d'origen marroquí a Catalunya. Collecció Ciutadania i Immigració, 3. Secretaria per a la Immigració. Generalitat de Catalunya.

Nash, M. (2006) «Identidades de género, mecanismos de subalternidad y procesos de emancipación femenina» Revista CIDOB d'Afers Internacionals, 73-74:39-57.

PÀmies, J. (2006) Dinámicas escolares y comunitarias de los hijos e hijas de familias inmigradas marroquies de la Yebala en la periferia de Barcelona. Tesi doctoral. Barcelona: Departament d'Antropologia Social i Cultural, Universitat Autònoma de Barcelona.

Ramírez Fernández, Á. (1998) Migraciones, género e islam: mujeres marroquíes en España. Madrid: AECI.

SPINDler, G. (1987) «The transmission of culture». A SPINDlER, G. (eds.) Education and cultural process. Anthropological approaches. Illinois: Waveland Press, Inc. Prospects Heights-Illinois. 303-334.

TAYlor, S.J. i Bogdan, R. (1987) Introducción a los métodos cualitativos de investigación. Barcelona: Paidos. 